\title{
……
}

CLINICAL RESEARCH

\section{Randomized controlled trial comparing immediate loading with conventional loading using cone-anchored implant- supported screw-retained removable prostheses: A 2-year follow-up clinical trial}

\author{
Lauren Bernard, DDS, ${ }^{a}$ Marjolein Vercruyssen, DDS, PhD, ${ }^{b}$ Julie Vanderveken, DDS, ${ }^{c}$ Wim Coucke, PhD, ${ }^{d}$ \\ Marc Quirynen, DDS, PhD, ${ }^{e}$ and Ignace Naert, DDS, $\mathrm{PhD}^{\mathrm{f}}$
}

Osseointegrated dental implants can provide edentulous patients with stability and retention of their maxillary prostheses $^{1,2}$ and improved quality of life. ${ }^{3-6}$ Different mechanisms, such as bar and stud attachments, are available to connect the prosthesis to the implants. ${ }^{7,8}$ An additional connection option is the implant-supported telescope and cone-anchored overdentures (OD). ${ }^{9}$ A 3-year prospective study by Zou et $\mathrm{al}^{10}$ reported no differences in implant outcomes between overdentures anchored by telescopic, bar, or stud attachments on 4 maxillary implants.

The SynCone (Dentsply Sirona) is an abutment with a double-cone design fitting on an Ankylos implant (Dentsply Sirona) (Fig 1). ${ }^{11,12}$ The AnkylosSynCone transfers the stability of

\begin{abstract}
Statement of problem. Implant-based prosthetic solutions can be time consuming. If implants can be loaded immediately, treatment time can be reduced.

Purpose. The purpose of this prospective randomized controlled trial was to monitor the survival rate of Ankylos implants, comparing conventional with immediate loading by using abutments with the SynCone concept for screw-retained removable prostheses in the edentulous maxilla.

Material and methods. A total of 90 implants were placed in 15 study participants. The participants were randomly assigned to the immediate or conventional loading treatment group. Radiographic and clinical parameters were recorded at the time of permanent prosthesis installment and at 1- and 2-year follow-up examinations, and participants' satisfaction was measured by using questionnaires before and after prosthesis installation. A linear mixed model was used to measure differences.

Results. One implant in the conventional group was lost during abutment placement; hence, 89 implants could be followed for 2 years. Approximately $90 \%$ of these implants showed no bone loss or even bone gain at 1 and 2 years follow-up. Mean values for the immediate group were, respectively, $0.09 \pm 0.35 \mathrm{~mm}$ and $0.13 \pm 0.38 \mathrm{~mm}$ and $0.01 \pm 0.41 \mathrm{~mm}$ and $-0.06 \pm 0.32 \mathrm{~mm}$ for the conventional method. No significant differences $(P=.053)$ were found in bone level alterations between the groups. For all participants, the mean number of surfaces (4 per implant) with bleeding on probing (BoP) and plaque were $0.76 \pm 0.81$ and $0.16 \pm 0.42$ at 1 year follow-up and $0.44 \pm 0.66$ and $0.02 \pm 0.15$, respectively, at the second-year follow-up. The mean pocket probing depths were 2.05 $\pm 0.54 \mathrm{~mm}$ at 1 year and $2.18 \pm 0.64 \mathrm{~mm}$ at 2 years. For both groups, a significant rise in satisfaction and quality of life was observed $(P \leq .001)$ at 1 and 2 years compared with pretreatment.

Conclusions. Ankylos implants placed in the edentulous maxilla, immediately or conventionally loaded by a detachable prosthesis, showed favorable bone-level preservation after 2 years of follow-up. No significant differences could be found between the immediate and conventional groups. A significant increase in quality of life was observed for both loading modes. (J Prosthet Dent 2018
\end{abstract}

\footnotetext{
I.N. and M.Q. hold Dentsply Implant Chairs for Implant-Supported Oral Rehabilitation.

${ }^{a}$ Assistant, Department of Oral Health Sciences, KU Leuven and Dentistry, Periodontology, University Hospitals Leuven, Leuven, Belgium.

bPostdoctoral researcher, Department of Oral Health Sciences, KU Leuven and Dentistry, Periodontology, University Hospitals Leuven, Leuven, Belgium.

${ }^{\mathrm{c}}$ Assistant, Department of Oral Health Sciences, KU Leuven and Dentistry, Prosthetic Dentistry, University Hospitals Leuven, Leuven, Belgium.

${ }^{\mathrm{d} C}$ Consultant, Scientific Institute of Public Health, Brussels, Belgium.

eProfessor and Chief, Department of Oral Health Sciences, KU Leuven and Dentistry, Periodontology, University Hospitals Leuven, Leuven, Belgium.

fProfessor-emeritus, Department of Oral Health Sciences, KU Leuven and Dentistry, Prosthetic Dentistry, University Hospitals Leuven, Leuven, Belgium.
} 


\section{Clinical Implications}

If there are no differences in implant survival, bone loss, or clinical parameters, immediate loading can be used more commonly. This would reduce treatment time for the patient and may result in a more rapid increase in quality of life.

the tapered abutment connection to the abutmentprosthesis connection. ${ }^{11,12}$ This second tapered connection ensures that the definitive restoration is tightly seated, minimizing gaps and micromovement. ${ }^{11,12}$ The internal part of the abutment fits into the implant lumen with a conical Morse taper connection, whereas the external part, which is also conical, allows a gold fitted cap to be seated on top and provides frictional retention for the prosthesis. ${ }^{13}$ The abutments are available as stock abutments, so they are typically less expensive than the telescope technique that needs customized fabrication. ${ }^{13}$ In vitro data suggest that by using secondary splinting with this design, a more favorable force transfer can be obtained onto individual implants, with an almost constant retentive force during the entire testing cycle. ${ }^{14,15}$ This concept allows the prosthesis to be removed but offers the comfort of a fixed partial denture. ${ }^{16}$ The interimplant spaces and space between fixed partial denture and soft tissues are fully closed, which helps overcome phonetic problems and saliva release. ${ }^{17-19}$ Oral hygiene is simplified because of the easy access to all implants when the prosthesis is removed. ${ }^{20}$ Good oral hygiene is a determining factor for dental implant survival. ${ }^{21,22}$

The Ankylos implant has been available since 1987, with only minor changes to the design. ${ }^{23}$ Krebs et al ${ }^{24}$ conducted a 20-year longitudinal study of the system, concluding that the peri-implant bone loss was low, with only $4.8 \%$ of implants with $2 \mathrm{~mm}$ or more bone loss. The cumulative survival rate (CSR) of this implant after 20 years was $94.7 \%$ for the maxilla and $92.1 \%$ for the mandible.

Immediately loaded implants for overdentures generally have high survival rates. ${ }^{25-27}$ Romanos and Nentwig ${ }^{28}$ reported a survival rate of $96.7 \%$ after 6.5 years of follow-up. The most important advantage of immediate loading is the reduction in treatment time, providing earlier comfort and esthetics for the patient and less chair time. ${ }^{29}$

The purpose of the current prospective randomized controlled clinical trial was to monitor the survival rate of implants, comparing conventional with immediate loading with a screw-retained prosthesis in the edentulous maxilla. The null hypothesis was that no differences would be found in bone loss or quality of life between the groups.

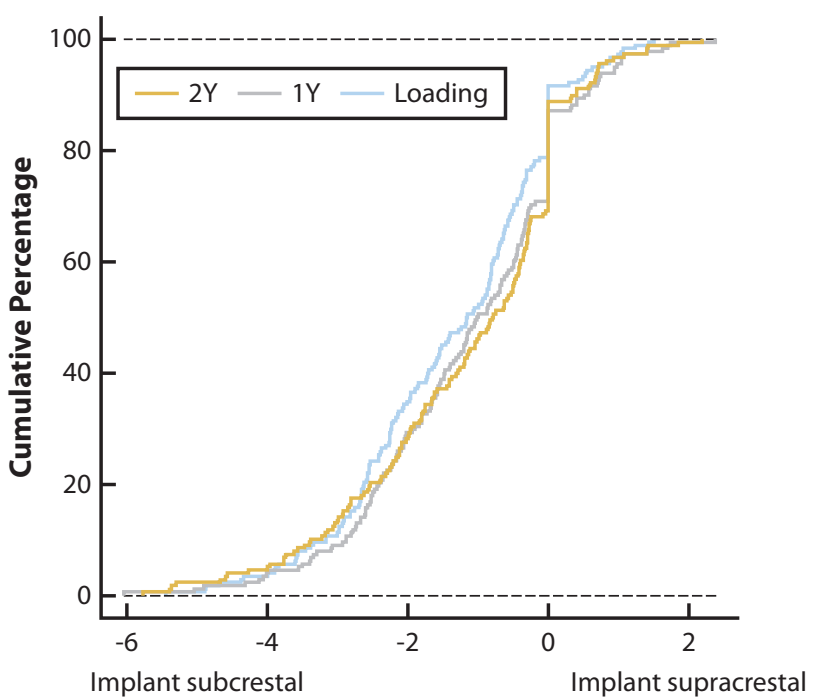

Bone Level Mesial-Distal

Figure 1. Cumulative percentage distribution of mesial and distal bone level measurements at loading, year 1 , and year 2 .

Table 1. Inclusion and exclusion criteria

\begin{tabular}{|c|c|}
\hline Inclusion criteria & Exclusion criteria \\
\hline $\begin{array}{l}1 \text { Provision of informed consent } \\
218 \text { years or older } \\
3 \text { Extraction sockets should have healed at } \\
\text { least } 4 \text { months } \\
4 \text { Sufficient bone volume to place six } \\
\text { implants in the maxilla } \\
5 \text { No previous bone augmentation } \\
\text { procedures } \\
6 \text { The mandible can have any kind of } \\
\text { dentition if a well-distributed contact } \\
\text { relationship with the new prosthesis } \\
\text { in the maxilla can be established. } \\
7 \text { Accepting to comply with study } \\
\text { procedures }\end{array}$ & $\begin{array}{l}1 \text { Physical or psychological } \\
\text { disorders prohibiting } \\
\text { implant treatment } \\
2 \text { Heavy smoking ( }>10 \\
\text { cigarettes/day) } \\
3 \text { Present alcohol and/or } \\
\text { drug abuse } \\
4 \text { Physical disability that } \\
\text { may interfere with the } \\
\text { ability to perform oral } \\
\text { hygiene }\end{array}$ \\
\hline
\end{tabular}

Reprinted with permission from Vercruyssen et al. ${ }^{30}$

\section{MATERIAL AND METHODS}

This study was designed as a randomized controlled trial. Participants were selected from patients with maxillary edentulism in need of a maxillary rehabilitation visiting the departments of Restorative Dentistry or Periodontology at the Saint Rafael Hospital. The information about study participants with inclusion and exclusion criteria and groups is shown in Tables 1 and 2. More detailed information has been published previously. ${ }^{30}$

The study was approved by the ethical committee of the University Hospital (B32220096198) and by the Federal Agency for Medicines and Health Products (Health Authority). This study is registered with the U.S. National Institutes of Health Clinical Trials registry (NCT03041597). All participants provided signed consent.

All participants underwent a multislice computed tomography scan (Somatom Definition Flash; Siemens AG) at $120 \mathrm{kV}$ and $90 \mathrm{mAs}$; 0.6-mm slice thickness; voxel size, 
Table 2. Participants and implant features

\begin{tabular}{lcc}
\hline Participants & $\begin{array}{c}\text { Immediate } \\
\text { Group }\end{array}$ & $\begin{array}{c}\text { Conventional } \\
\text { Group }\end{array}$ \\
\hline Total participants & 7 & 8 \\
\hline Sex (males/females) & $5 / 2$ & $7 / 1$ \\
\hline Age range $(\mathrm{y})^{*}$ & $45-71$ & $49-70$ \\
\hline Smokers & 1 & 1 \\
\hline No. of implants placed & 42 & 48 \\
\hline No. of implants analyzed & 42 & 47 \\
\hline No. of implants lost before loading & 0 & 1 \\
\hline Implant diameter $(3.5 \mathrm{~mm} / 4.5 \mathrm{~mm})$ & $34 / 8$ & $39 / 9$ \\
\hline Implant length $(9.5 / 11 / 14 \mathrm{~mm})$ & $0 / 20 / 22$ &
\end{tabular}

$330 \mathrm{~lm}$. The participant was positioned in centric relationship with a scan prosthesis and occlusion index positioned in the mouth. The implants were planned by a periodontist (M.V.) in the optimal position considering the available bone and prosthesis. The scan prosthesis contained all the information for the definitive prosthesis. Randomization was done by a randomization table provided by an external statistician. Six implants (Ankylos; Dentsply Sirona) were placed with a flapless technique with the participant under local anesthesia, using a stereolithographic guide fixed to the underlying bone by 3 or 4 anchor pins.

Participants in the conventional group received the definitive prosthesis after 3 months. After the placement of the healing abutments, the definitive prosthesis was prepared. This was done preoperatively for the immediate loading group. A soft tissue cast was prepared by using a duplicate of the stereolithographic guide, and the definitive prosthesis was fabricated. Immediately after implant surgery, the correct interimplant position was determined from an impression at the implant level. This was used in the laboratory to pour a cast and to finalize the abutment selection. The next day the implants were loaded with the definitive prostheses. More detailed information about the planning and the prosthetic procedures can be found elsewhere. ${ }^{30}$

Clinical parameters were evaluated at placement and at the 1- and 2-year follow-up visits. For the immediate group, the data at loading were scored 10 days after implant placement. Plaque was scored as absent (0) or present (1) at 4 sites (mesial, distal, buccal, lingual) of each abutment. ${ }^{31}$ Bleeding on probing (BoP) was recorded 20 seconds after gentle probing as no bleeding (0) or bleeding (1). ${ }^{32}$ For both parameters, the total score per abutment was calculated. Probing depths and recession or clinical attachment loss was recorded with the implant-abutment junction as the reference level, using a Merritt-B periodontal probe (Hu-Fiedy). These parameters were also scored at the 4 positions around each implant.

Each participant completed 3 questionnaires during treatment: before implant placement and at 1 year and then 2 years after prosthesis placement. This questionnaire was used to estimate satisfaction with the existing and new prostheses. Using a visual analog scale (VAS), participants scored prosthesis retention, comfort, speech, function, esthetics, self-esteem, and the feeling of "being my own teeth." The VAS consisted of 20 questions in the participants' language (Dutch). Examples were "Can you eat well with your current prosthesis?", "Can you talk well?", "Are you content with the current situation?" Participants were asked to mark a cross on a line anchored by 0 (very bad) to 10 (very good). Subsequently, the VAS score was measured in relative lengths. These values were used to evaluate the satisfaction and thus the quality of life of the participants before and after the treatment. All questionnaires were statistically compared to assess any change in quality of life.

During the study period, adverse events with the implants or prostheses were monitored. At each followup visit, participants' medical histories were updated, and dropouts or withdrawals were registered.

Radiographs were made with a phosphor plate (Digora; Soredex) in a parallel position with the x-ray beam (Minray, 60kV, 7mA; Soredex) perpendicular to the implant. Radiographs were made at loading (baseline and at 1 and 2 year follow-up examinations). Each radiograph was calibrated individually by using the whole implant and/or the thread pitch distance to correct for deformation or magnification. Marginal bone loss was determined both at the mesial and at the distal sites of each implant by measuring the distance between the implant shoulder and the most coronal bone-to-implant contact by using image processing software (ImageJ for Windows; U.S. National Institutes of Health). ${ }^{33}$ All measurements were made by an independent examiner (L.B.) who was not involved in the treatment process and who was blinded to the intervention. Bone loss over time was calculated for each mesial and distal site.

Bone loss, probing depths, and number of BoP sites were visualized by means of an empirical cumulative distribution function. Differences for bone loss were modeled by a linear mixed model with time and group (conventional or immediate) as crossed fixed factors and patient as random factors. Differences between group types were calculated after 1 year and after 2 years, and a correction for simultaneous hypothesis testing was made according to Sidak. ${ }^{34}$ The model's assumptions were verified by a normal quantile plot of the residual values. Subsequently, a post hoc analysis was done and a correction according to Sidak was applied. ( $\mathrm{N}$ value $>20$ ).

The questionnaires were analyzed by a linear mixed model fit with randomization treatment and visit at 2 crossed fixed factors and patient as a random factor. Normal quantile plots and residual dot plots proved the 


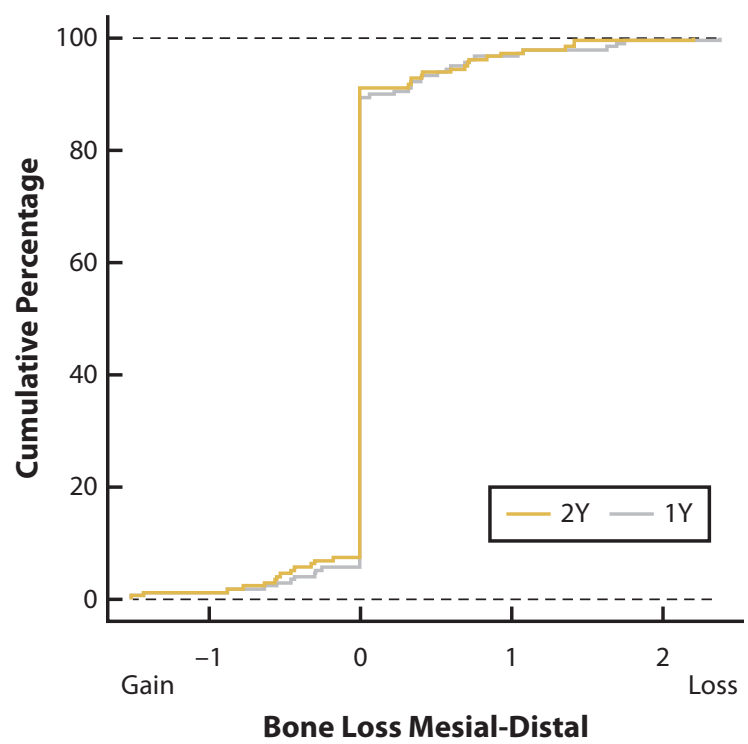

Figure 2. Cumulative percentage distribution of mesial and distal bone loss measurements comparing loading to year 1 and year 2 .

Table 3. Mean \pm standard deviation bone loss

\begin{tabular}{lccc}
\hline Group & $\begin{array}{c}\text { Immediate } \\
(\mathbf{m m})\end{array}$ & $\begin{array}{c}\text { Conventional } \\
(\mathbf{m m})\end{array}$ & $\begin{array}{c}\text { Immediate and } \\
\text { Conventional }(\mathbf{m m})\end{array}$ \\
\hline Year 1-loading & $0.09 \pm 0.35$ & $0.01 \pm 0.41$ & $0.05 \pm 0.38$ \\
\hline Year 2-loading & $0.13 \pm 0.38$ & $-0.06 \pm 0.32$ & $0.03 \pm 0.36$ \\
\hline
\end{tabular}

Between treatment groups, no significant differences in bone loss observed ( $P>.132$. Negative value represents bone gain.

adequacy of the model. Multiple comparisons between groups were corrected for simultaneous hypothesis testing according to Sidak.

\section{RESULTS}

A total of 90 implants were inserted $(\varnothing, 3.5$ or $4.5 \mathrm{~mm}$; length, 9.5 to $14 \mathrm{~mm}$ ). Six implants were placed in every study participant. Twenty-five prospective participants were screened for the study, but only 15 met inclusion or exclusion criteria. All participants complied with the recall schedule. Implants were placed between February 2010 and December 2013. Seven participants were enrolled in the immediate group and 8 in the conventional (control) group.

One implant in the conventional group was lost during abutment placement due to nonosseointegration. Hence, a total of 89 implants were followed during 2 years of loading. No implant was lost during this period. Details of participants and implant features are shown in Table 2.

Most implants were placed subcrestally (Fig. 1), on average, $2.0 \pm 1.3 \mathrm{~mm}$ for the immediate and $0.8 \pm 1.0 \mathrm{~mm}$ for the conventional group. This relative position of the alveolar crest toward the implant did not show major changes over time.

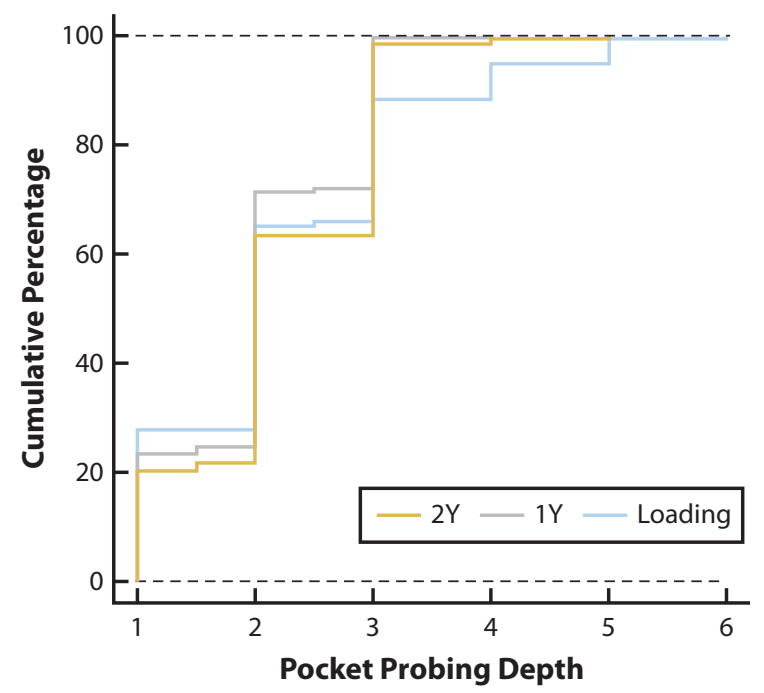

Figure 3. Cumulative percentage distribution of pocket probing depths at loading, year 1 , and year 2 .

The cumulative percentage of bone loss, both mesial and distal, for all implants is shown in Figure 2. Approximately $90 \%$ of the implants showed no bone loss or showed bone gain at 1 and 2 years. The mean \pm SD bone losses for the immediate group were $0.09 \pm 0.35 \mathrm{~mm}$ and $0.13 \pm 0.38 \mathrm{~mm}$ and $0.01 \pm 0.41 \mathrm{~mm}$ and $-0.06 \pm 0.32$ $\mathrm{mm}$ for the conventional group at the 1- and 2-year follow-up examinations (Table 3). No significant intergroup differences were found, either at the 1- or 2-year follow-up (P>.053).

Almost $100 \%$ of the implant sites showed probing depths of $\leq 3 \mathrm{~mm}$ after 2 years' follow-up (Fig. 3). At loading, the mean \pm SD probing depths for the immediate group were $2.4 \pm 0.9 \mathrm{~mm}$ and $2.1 \pm 0.7 \mathrm{~mm}$ for the conventional group. These probing depths were reduced after the first year to $2.0 \pm 0.6 \mathrm{~mm}$ and $2.1 \pm 0.5$ $\mathrm{mm}$. After the second year, a slight increase was measured; $2.2 \pm 0.6 \mathrm{~mm}$ for the immediate group and $2.2 \pm 0.7 \mathrm{~mm}$ for the conventional group. No recession was observed up to the first year of follow-up, and only a few areas of recession were recorded after 2 years (Table 4).

After 2 years, more than $60 \%$ of the implant sites showed no BoP (Fig. 4). The mean \pm SD number of sites with BoP (scores of $0-4$ per implant) at loading was $0.90 \pm 1.46$ for the immediate group and $0.23 \pm 0.60$ for the conventional group. An increase in BoP was measured in the conventional group at 1-year follow-up $(0.87 \pm 0.82)$. However, this number dropped to 0.45 \pm 0.65 at year 2 . For the immediate group, the number of implants with BoP kept decreasing at the 1-year (0.64 $\pm 0.79)$ and 2 -year follow-up $(0.43 \pm 0.67)$ examinations. The plaque score at the 1 -year follow-up was $0.12 \pm 0.45$ for the immediate group and $0.19 \pm 0.40$ for the conventional group. These numbers decreased to $0.00 \pm 0.00$ 
Table 4. Bleeding on probing, probing depths, and attachment loss as measured at different time points

\begin{tabular}{|c|c|c|c|c|c|c|c|c|c|c|c|}
\hline \multirow[b]{2}{*}{ Variable } & \multicolumn{3}{|c|}{ Loading } & \multicolumn{4}{|c|}{ Year 1} & \multicolumn{4}{|c|}{ Year 2} \\
\hline & BoP & PPD & AL & Plaque & BoP & PPD & AL & Plaque & BoP & PPD & AL \\
\hline \multicolumn{12}{|l|}{ IM } \\
\hline Mean & 0.90 & 2.44 & 0.00 & 0.12 & 0.64 & 2.04 & 0.00 & 0.00 & 0.43 & 2.18 & 0.02 \\
\hline$\pm \mathrm{SD}$ & 1.46 & 0.92 & 0.00 & 0.45 & 0.79 & 0.56 & 0.00 & 0.00 & 0.67 & 0.59 & 0.12 \\
\hline \multicolumn{12}{|l|}{ DL } \\
\hline Mean & 0.23 & 2.06 & 0.00 & 0.19 & 0.87 & 2.05 & 0.00 & 0.04 & 0.45 & 2.17 & 0.05 \\
\hline$\pm \mathrm{SD}$ & 0.60 & 0.70 & 0.00 & 0.40 & 0.82 & 0.52 & 0.00 & 0.20 & 0.65 & 0.70 & 0.12 \\
\hline \multicolumn{12}{|l|}{$\mathrm{IM}+\mathrm{DL}$} \\
\hline Mean & 0.55 & 2.21 & 0.00 & 0.16 & 0.76 & 2.05 & 0.00 & 0.02 & 0.44 & 2.18 & 0.03 \\
\hline$\pm \mathrm{SD}$ & 1.13 & 0.86 & 0.00 & 0.42 & 0.81 & 0.54 & 0.00 & 0.15 & 0.66 & 0.64 & 0.12 \\
\hline
\end{tabular}

AL, attachment loss; BoP, bleeding on probing; DL, conventional group; IM, immediate group; IM+DL, all groups; PPD, probing pocket depth; SD, standard deviation.

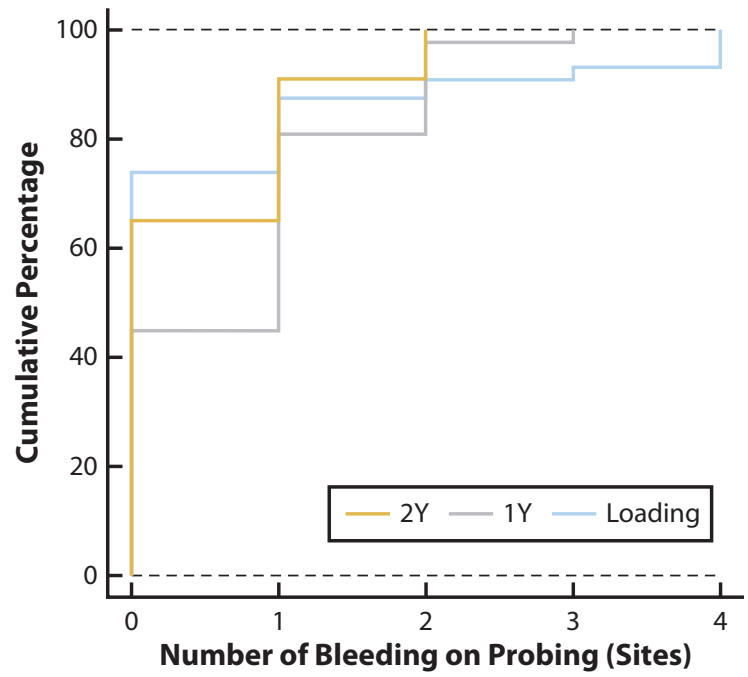

Figure 4. Cumulative percentage distribution of bleeding on probing sites at loading, year 1 , and year 2 .

for the immediate group and $0.04 \pm 0.20$ for the conventional group at year 2 .

A significant rise in satisfaction and quality of life was observed at 1- and 2-year follow-up examinations compared with the situation before treatment for both groups $(P \leq .001)$ (Table 5$)$. The overall mean score improved from $64 \%$ ( $0 \%$ correlates with highest dissatisfaction and $100 \%$ with highest satisfaction) before to $89 \%$ at the 2-year follow-up. A slight increase in mean value was found at the 2-year follow-up compared with that at the 1-year follow-up (86\%). However, this was not significant $(P=.676)$. No differences between the groups were measured. $(P=.831)$.

\section{DISCUSSION}

The research hypothesis that no differences in bone loss or quality of life wound be found between the groups was confirmed by the study. Strict inclusion and exclusion criteria suggest that good diagnosis and screening of the patient are necessary to treat the patient optimally. The observations in this clinical study are consistent with the
Table 5. Responses on questionnaires from different groups at different time points

\begin{tabular}{lccc}
\hline & \multicolumn{3}{c}{ Group } \\
\cline { 2 - 4 } Time Point & Immediate & Conventional & Both Group \\
\hline Before (\%) & & & \\
\hline Mean & 65.5 & 63.7 & 64.4 \\
\hline \pm SD & 14.9 & 8.2 & 10.2 \\
\hline Maximum & 86.4 & 74.8 & 79.8 \\
\hline Minimum & 34.3 & 41.4 & 38.1 \\
\hline After 1 y (\%) & & & $86.1^{*}$ \\
\hline Mean & $84.5^{*}$ & $87.6^{*}$ & 4.4 \\
\hline \pm SD & 7.3 & 2.9 & 92.3 \\
\hline Minimum & 93.1 & 91.5 & 73.3 \\
\hline Maximum & 66.4 & 78.5 & \\
\hline After 2 y (\%) & & & $89.2^{*}$ \\
\hline Mean & $87.0^{*}$ & $91.0^{*}$ & 3.9 \\
\hline \pm SD & 5.4 & 3.6 & 93.6 \\
\hline Maximum & 94.3 & 94.9 & 77.6 \\
\hline Minimum & 76.4 & 76.5 &
\end{tabular}

$\mathrm{SD}$, standard deviation. ${ }^{*} P \leq .001$ compared with before treatment.

systematic review by Esposito et $\mathrm{al}^{26}$ who reported no differences between different loading regimens for prosthesis success, implant success, or marginal bone levels. The bone level at baseline was located, on average, $1.4 \pm 1.3 \mathrm{~mm}$ more coronally of the reference point on the implant. This was due to the protocol which allowed subcrestal implant placement. ${ }^{11}$ Furthermore, no statistical differences in bone loss were found between the immediate and conventional group (Table 3). Suarez et al ${ }^{27}$ concluded in their systematic review that the timing for restorations of implants does not affect marginal bone loss.

In the current study, plaque scores and BoP remained low; these results can be partially explained by the fact that the implants were not splinted and the prosthesis could be removed, which facilitated accessibility to both implants and prostheses. This observation is consistent with the study by Eitner et al, ${ }^{9}$ who reported higher sulcus fluid flow rate for bar versus telescopic ODs. 
The CSRs of this study are comparable with those of other long-term clinical studies of cone-anchored implants. One 5-year follow-up study reported survival rates of $96.6 \%$, and another 20-year follow-up study reported a CSR of $94.7 \%$ in the maxilla. ${ }^{16,24}$ Eccellente et $\mathrm{al}^{11}$ and Romanos et $\mathrm{al}^{20}$ used the same system on immediately loaded implants. They published survival data of $97.7 \%$ at 26 months and $94 \%$ at 54 months. A systematic review of the 5 -year survival rate of conventional loading was published in 2009, in which the average bone loss was $0.6 \mathrm{~mm}$ for all indications.

The average bone level results are similar to those of Donovan et $\mathrm{al}^{23}$ who reported bone levels of $1.4 \mathrm{~mm}$ mesially and $1.3 \mathrm{~mm}$ distally subcrestally at surgery. They also reported no statistically significant correlation regarding the degree of subcrestal implant position and future loss of hard tissue.

A randomized controlled clinical trial by Rocha et $\mathrm{al}^{33,35}$ showed significantly more bone preservation around implants with platform-switching restorations. After the initial bone remodeling, the platform-switching group showed bone gain of $0.16 \pm 0.54 \mathrm{~mm}$ compared with the regular platform group $-0.08 \pm 0.52 \mathrm{~mm}$ during a 3 -year follow-up. They observed bone gain in $72 \%$ of the implants with platform switching. This could reflect a certain capacity to reverse the initial bone loss. This was also observed in the present study. The mean bone loss in this study was $0.03 \pm 0.36 \mathrm{~mm}$. Optimal oral hygiene could also explain the very favorable bone data in our patient group. Mombelli et $\mathrm{al}^{21}$ stated that good oral hygiene is the prerequisite for successful implant outcomes. Wismeijer et $\mathrm{al}^{22}$ reported less soft tissue bleeding in single-stud ODs compared with bar ODs as a result of reduced plaque accumulation.

The participants in the present study reported an increase in quality of life. Recently, Yamada et $\mathrm{al}^{3}$ published a prospective clinical study of immediate loading in the edentulous maxilla. They reported a clinically relevant improvement in oral health-related quality of life. This improvement was significant after prosthetic treatment. Another study confirmed these findings. ${ }^{4}$

The design of the screw-retained removable prosthesis ensures excellent comfort, comparable with a complete fixed dental prosthesis. ${ }^{5}$ No interimplant open space is required. Lip support is easily managed with this design. It overcomes the phonetic and saliva-spitting problems that may occur with complete fixed dental prostheses. ${ }^{18,19,36}$

In the study by Zou et $\mathrm{al}^{10}{ }^{10}$ most participants responded with VAS scores of $<50 \%$ with their existing dentures. After 1 year with their new prostheses, patients' satisfaction improved more than $80 \%$. This is similar to the study by Eerdekens et $\mathrm{al}^{16}{ }^{16}$ Morris et $\mathrm{al}^{6}$ reported increasing VAS ratings for comfort and self-esteem up to 3 years with a new prosthesis before leveling, which is consistent with the results of the present study with a slight improvement at the 2-year follow-up.

The present study had insufficient power to measure survival differences between the immediate and conventional group. Fewer participants than intended were included because the strict inclusion and exclusion criteria restricted recruitment. Longer follow-up time and larger groups are suggested for future research.

\section{CONCLUSIONS}

Within the limitations of this randomized controlled clinical trial, the following conclusions were drawn:

1. Ankylos implants placed in an edentulous maxilla, either immediately or conventionally loaded by a screw-retained prosthesis (SynCone concept), showed favorable bone-level preservation after 24 months of follow-up.

2. No significant differences in bone loss or quality of life could be found between the immediate and conventional group $(P>$.053).

3. A significant increase $(P \leq .001)$ in quality of life was observed for both loading modes after definitive prosthesis placement.

\section{REFERENCES}

1. Besimo C, Graber G. A new concept of overdentures with telescope crowns on osseointegrated implants. Int J Periodontics Restorative Dent 1994;14 486-95.

2. Romanos GE. Surgical and prosthetic concepts for predictable immediate loading of oral implants. J Calif Dent Assoc 2004;32:991-1001.

3. Yamada J, Kori H, Tsukiyama Y, Matsushita Y, Kamo M, Koyano K. Immediate loading of complete-arch fixed prostheses for edentulous maxillae after flapless guided implant placement: a 1-year prospective clinical study. Int Oral Maxillofac Implants 2015;30:184-93.

4. Pjetursson BE, Karoussis I, Bürgin W, Brägger U, Lang NP. Patients' satisfaction following implant therapy: a 10-year prospective cohort study. Clin Oral Implants Res 2005;16:185-93.

5. Mertens C, Steveling HG. Implant-supported fixed prostheses in the edentulous maxilla: 8-year prospective results. Clin Oral Implants Res 2011;22: 464-72.

6. Morris HF, Ochi S, Rodriguez A, Lambert PM. AICRG, part IV: patient satisfaction reported for Ankylos implant prostheses. J Oral Implantol 2004;30:152-61.

7. Slot W, Raghoebar GM, Vissink A, Huddleston Slater IJ, Meijer HI. A systematic review of implant-supported maxillary overdentures after a mean observation period of at least 1 year. J Clin Periodontol 2010;37:98-110.

8. Att W, Bernhart J, Strub JR. Fixed rehabilitation of the edentulous maxilla: possibilities and clinical outcome. I Oral Maxillofac Surg 2009;67:60-73.

9. Eitner S, Schlegel A, Emeka N, Holst S, Will J, Hamel J. Comparing bar and double-crown attachments in implant-retained prosthetic reconstruction: a follow-up investigation. Clin Oral Implants Res 2008;19:530-7.

10. Zou D, Wu Y, Huang W, Wang F, Wang S, Zhang Z, et al. A 3-year prospective clinical study of telescopic crown, bar, and locator attachments for removable four implant-supported maxillary overdentures. Int J Prosthodont 2013:26:566-73.

11. Eccellente T, Piombino M, Piattelli A, Perrotti V, Iezzi G. A new treatment concept for immediate loading of implants inserted in the edentulous mandible Quintessence Int 2010:41:489-95.

12. Cepa S, Koller B, Wolkewitz M, Kohal R. Implant-retained prostheses: ball vs. conus attachments: a randomized controlled clinical trial. Clin Oral Implants Res. 2017:28:177-85.

13. Šidàk Z. Rectangular confidence region for the means of multivariate normal distributions. J Am Stat Assoc 1967;62:626-33.

14. Zhang R-G, Hannak WB, Roggensack M, Freesmeyer WB. Retentive characteristics of Ankylos SynCone conical crown system over long-term use in vitro. Eur J Prosthodont Restor Dent 2008;16:61-6. 
15. Besimo C, Kempf B. In vitro investigation of various attachments for overdentures on osseointegrated implants. J Oral Rehabil 1995;22: 691-8.

16. Eerdekens L, Schols M, Coelst L, Quirynen M, Naert IA. 5-year prospective study on cone-anchored implants in the edentulous maxilla. Clin Implant Dent Relat Res 2015;17:621-32.

17. Lundqvist S, Haraldson T, Lindblad P. Speech in connection with maxillary fixed prostheses on osseointegrated implants: a three-year follow-up study. Clin Oral Implant Res 1992;3:176-80.

18. Jacobs R, Manders E, Van Looy C, Lembrechts D, Naert I, van Steenberghe D. Evaluation of speech in patients rehabilitated with various oral implant-supported prostheses. Clin Oral Implants Res 2001;12: 167-73.

19. Van Lierde KM, Browaeys H, Corthals P, Matthys C, Mussche P, Van Kerckhove E, et al. Impact of fixed implant prosthetics using the "all-on-four" treatment concept on speech intelligibility, articulation and oromyofunctional behaviour. Int J Oral Maxillofac Implants 2012;41:1550-7.

20. Besimo C, Graber G, Schaffner T. Hybrid prosthesis implant-supported superstructures in edentulous jaw. 1. Case planning. ZWR 1991;100: 12-6.

21. Mombelli A, Müller N, Cionca N. The epidemiology of peri-implantitis. Clin Oral Implants Res 2012;23:67-76.

22. Wismeijer D, van Waas MA, Mulder J, Vermeeren JI, Kalk W. Clinical and radiological results of patients treated with three treatment modalities for overdentures on implants of the ITI dental implant system. A randomized controlled clinical trial. Clin Oral Implants Res 1999;10:297-306.

23. Donovan R, Fetner A, Koutouzis T, Lundgren T. Crestal bone changes around implants with reduced abutment diameter placed non-submerged and at subcrestal positions: a 1-year radiographic evaluation. J Periodontol 2010;81:428-34

24. Krebs M, Schmenger K, Neumann K, Weigl P, Moser W, Nentwig GH Long-term evaluation of Ankylos dental implants, part I: 20-year life table analysis of a longitudinal study of more than 12,500 implants. Clin Implant Dent Relat Res 2015;17(suppl 1):e275-86.

25. Romanos GE, May S, May D. Implant-supporting telescopic maxillary prostheses and immediate loading. Clin Implant Dent Relat Res 2014;16: 412-8.

26. Esposito M, Grusovin MG, Willings M, Coulthard P, Worthington HV. The effectiveness of immediate, early, and conventional loading of dental implants: a Cochrane systematic review of randomized controlled clinical trials Int J Oral Maxillofac Implants 2008;22:893-904.
27. Suarez F, Chan H-L, Monje A, Galindo-Moreno P, Wang H-L. Effect of the timing of restoration on implant marginal bone loss: a systematic review J Periodontol 2013;84:159-69.

28. Romanos GE, Nentwig GH. Immediate functional loading in the maxilla using implants with platform switching: five-year results. Int J Oral Maxillofac Implants 2009;24:1106-12.

29. De Bruyn H, Raes S, Ostman P-O, Cosyn J. Immediate loading in partially and completely edentulous jaws: a review of the literature with clinical guidelines. Periodontol 2000;2014(66):153-87.

30. Vercruyssen M, Cox C, Naert I, Jacobs R, Teughels W, Quirynen M. Accuracy and patient-centered outcome variables in guided implant surgery: a RCT comparing immediate with conventional loading. Clin Oral Implants Res 2016;27:427-32

31. Orban B. Gemodificeerde Navy Plaque index. In: Parodontale indices II. 1972. p. 8.

32. Weinberg MA, Hassan H. Bleeding on probing: what does it mean. Gen Dent 2012;60:271-8.

33. Abràmoff MD, Magalhães PJ, Ram SJ. Image processing with imageJ. Biophotonics Int 2004;11:36-41.

34. Mcardle BF, Clarizio LF. An alternative method for restoring single-tooth implants. J Am Dent Assoc 2001;132:1269-73.

35. Rocha S, Wagner W, Wiltfang J, Nicolau P, Moergel M, Messias A, et al. Effect of platform switching on crestal bone levels around implants in the posterior mandible: 3 -years results from a multicentre randomized clinical trial. J Clin Periodontol 2016;43:374-82.

36. Jemt T. Fixed implant-supported prostheses in the edentulous maxilla. A fiveyear follow-up report. Clin Oral Implant Res 1994;5:142-7.

\section{Corresponding author:}

Dr Lauren Bernard

Catholic University Leuven

UZ St. Raphael, Department of Periodontology

Kapucijnenvoer 33, B-3000 Leuven

BELGIUM

Email: info@parobernard.be

Acknowledgments

The authors thank Dentsply Sirona for providing oral implants, prosthetic materials, and stereolithographic guides for this study.

Copyright @ $\odot 2018$ by the Editorial Council for The Journal of Prosthetic Dentistry. 